\title{
Recuperación electroquímica del agua del Alpechín del Aceite de Oliva, para evitar la contaminación del medio ambiente y su reutilización como agua de riego
}

\author{
José Fernando PAREDES \\ Universidad Nacional de La Rioja \\ joseferpar_524@yahoo.com.ar \\ Raquel BRITO \\ Universidad Nacional de La Rioja \\ raquelbri@live.com.ar
}

Recibido: 2 de noviembre del 2011

Enviado a evaluar: 5 de noviembre del 2011

Aceptado: 27 de julio del 2012

\begin{abstract}
RESUMEN
El proyecto se inicio en razón de la concientización por el deterioro del medio ambiente, es por ello que esta tesis aborda el tratamiento del efluente industrial que proviene de la elaboración del Aceite de Oliva que se denomina alpechín y que son vertidos sin tratamiento previo contaminando los suelos. Este proyecto propone tratar los efluentes para reducir las concentraciones de sus contaminantes a través de una nueva técnica que proviene de la Ingeniería Electroquímica, que se denomina Electrocoagulación en flujo continuo, con el objeto de poder utilizar este liquido como agua de riego. Los compuestos contaminantes del alpechín son los polifenoles que le confieren un efecto bactericida y lípidos en suspensión que al ser vertidos sobre el suelo producen la impermeabilización de la superficie.

En este caso se aplicara la electrocoagulación para solucionara la problemática planteada. Este método involucra el uso de celdas electrolíticas y electrodos metálicos de aluminio a través de los cuales se hace pasar corriente eléctrica continua, que producirá la descomposición de los fenoles, para transformarlos en hidrógeno y dióxido carbono, como así también provocara la floculación de los lípidos sobre la superficie del efluente para su posterior extracción.
\end{abstract}

Palabras clave: Ambiente, Alpechín, Aceite, residuos líquidos

Electrochemical recovery of water from the vegetable water in olive oil, to prevent contamination of the environment and the reuse as irrigation water

\begin{abstract}
The project began because of the awareness about the deterioration of the environment, which is why this thesis deals with the treatment of industrial effluent coming from the production of olive oil and vegetable water is known that untreated discharges are polluting soils. This project proposes to treat the effluent to
\end{abstract}


reduce the concentrations of contaminants through a new technique that comes from the Electrochemical Engineering, called continuous flow electrocoagulation, in order to use this liquid as irrigation water. OMW polluting compounds are polyphenols which give a bactericidal effect lipid suspension to be dumped on the ground cause the waterproofing of the surface. In this case applied to solve electrocoagulation the issues raised. This method involves the use of electrolytic cells and aluminum metallic electrodes through which electrical current is passed continuously, to produce the decomposition of phenols, transforming them into hydrogen and carbon dioxide, as well as would cause flocculation of lipids on the surface of the effluent for subsequent extraction

Keywords: Environment, Vegetable water, oil, liquid waste

\section{INTRODUCCIÓN}

El desarrollo de nuestra sociedad lleva implícito un elevado costo medioambiental, de cuya magnitud el ser humano sólo ha empezado a ser consciente en la última década. El conocimiento, cada vez más profundo de los complejos mecanismos que rigen la interacción actividad humana - medio ambiente y de las tendencias de cambio que sigue nuestro planeta, han provocado la sensibilización social y han convertido en la actualidad a la Ingeniería Ambiental en uno de los principales campos de investigación.

De este modo, en los últimos años se están desarrollando y aplicando numerosas tecnologías de tratamiento como la Ingeniería Electroquímica que tienen por objetivo, minimizar el impacto ambiental ocasionado por los vertidos de residuos sólidos, líquidos y/o gaseosos generados por las actividades humanas ${ }^{1}$.

En la Ingeniería Electroquímica existen diferentes técnicas para la depuración de efluentes líquidos entre las que podemos mencionar las siguientes:

- Electrodeposición (iones inorgánicos)

- Electrodiálisis (iones inorgánicos)

- Electrólisis (baja concentración de materia orgánica)

- Electrocoagulación (materia coloidal o grasas)

- Electroflotación (materia coloidal o grasas)

Estas nuevas técnicas en los últimos tiempos han demostrado grandes ventajas de uso, pero no llegan a pasar las etapas de laboratorio por las razones que se detallan a continuación:

1. La ingeniería electroquímica es una disciplina complicada que necesita conocimientos interdisciplinarios, y que no suele estar incluida en los planes de formación universitaria, por lo que generalmente no es de frecuente aplicación y por falta de conocimiento.

2. Solo recientemente se han empezado a disponer del equipamiento necesario para realizar adecuadamente los procesos electroquímicos.

${ }^{1}$ Coeuret, F. La Ingeniería Electroquímica 
3. Debe competir con procesos clásicos en explotación, por lo que tan solo se utiliza cuando el proceso electroquímico tiene asociado un costo muy inferior, o cuando es el único posible.

Entre los diversos tipos de agresiones al medio ambiente, probablemente una de las que más ha centrado la atención del mundo investigador en los últimos años, ha sido el vertido de efluentes líquidos procedentes de actividades urbanas, agroganaderas e industriales a los medios hidrológicos naturales. Esto ha sido así porque existe la conciencia de que el agua es un bien escaso, y el conocimiento de que de su correcta gestión depende en gran medida el funcionamiento de nuestra sociedad.

Desde el punto de vista medioambiental, la gestión adecuada para el tratamiento de estos efluentes es la recuperación de los compuestos, y su reutilización.

De este modo son comunes en el tratamiento de aguas, procesos unitarios físicos, tales como la sedimentación y la filtración; químicos, como la coagulación-floculación, sedimentación flotación y la oxidación; y biológicos, tales como la bio-oxidación o la fermentación anaerobia.

Sin embargo, existe un importante volumen de aguas residuales que no pueden o no deben ser sometidas a ninguno de los tratamientos anteriormente mencionados, es por ello que la selección de la técnica de tratamiento depende fundamentalmente de las características físico-químicas, biológicas y criterios económicos del efluente a tratar.

En este proyecto el líquido residual a tratar por una técnica electroquímica, para su posterior utilización como agua de riego, se denomina alpechín que posee un elevado poder contaminante, ya que para la obtención de aceite de oliva del procesado de $1.000 \mathrm{~kg}$ de aceituna, equivalen a la contaminación de una población de 500 a 1.000 personas $^{2}$.

La Universidad Nacional de La Rioja posee una fábrica de aceite de oliva, que cuenta con un equipo de proceso continuo de extracción de tres fases, en el que podemos mencionar las siguientes etapas:

1- Recepción de materia prima: La materia prima, proveniente tanto de plantaciones propias como de terceros, es recibida en planta donde se realiza la pesada de ingreso correspondiente, generando por cada ingreso los comprobantes requeridos para identificar procedencia de la fruta, propietario, cantidad ingresada y variedad.

2- Lavado: esta etapa se realiza en forma mecánica, empleando agua potable. El objetivo fundamental es eliminar la mayor cantidad de tierra, ramas, hojas etc. que puedan venir juntamente con los frutos y que de no ser eliminados, interferirían en la calidad del producto final. Finalizada esta etapa, los frutos pasan a la siguiente etapa.

3-Molienda: los frutos ya lavados ingresan a un molino de discos donde se realiza la molienda, a fin de obtener la pasta que pasará a la siguiente etapa del proceso.

2 Joseph Vives-Rego (Catedrático de Microbiología de la Universidad de Barcelona), Carlos Sala (Director General Técnico de Bio Specific Systems) y Orlando Díaz (Ingeniero Industrial de bio Specific Systems). 
4- Amasado: La pasta obtenida durante la molienda pasa a las amasadoras donde se amasa a temperatura entre $28{ }^{\circ} \mathrm{C}$ a $30^{\circ} \mathrm{C}$, durante 60 minutos, dependiendo de las características de la materia prima ingresada.

5- Centrifugación Horizontal: la pasta ya amasada, es conducida mediante una bomba a la centrifugadora horizontal donde se realiza, por efecto de la fuerza centrífuga, la separación del aceite del residuo semisólido (orujo), el agua y el aceite.

6- Centrifugación Vertical: este aceite es conducido a una segunda centrifugación en una centrífuga vertical donde básicamente se realiza un proceso de separación del aceite con el agua de vegetación (alpechín).

7-Almacenamiento: El aceite obtenido es almacenado en tanques, en una sala de almacenamiento que cumple con las condiciones de conservación (lugar seco, al resguardo de la luz solar directa, temperatura ambiente) para preservar las características del producto.

8- Fraccionamiento: Según requerimientos comerciales, el aceite es fraccionado en envases bromatológicamente aptos y etiquetados.

\section{MATRIZ CAUSA EFECTO DEL PROCESO DEL ACEITE DE OLIVA}

\begin{tabular}{|c|c|c|}
\hline \multicolumn{3}{|c|}{ PROCESO PRINCIPAL: Extracción del Aceite de Oliva } \\
\hline Pasos del Proceso & Aspectos & Efectos \\
\hline \multirow{3}{*}{$\begin{array}{l}\text { 1- Ingreso Materia } \\
\text { Prima }\end{array}$} & \multirow{3}{*}{$\begin{array}{l}\text { Transporte de aceitunas de la tolva } \\
\text { de recepción a la cinta transportadora }\end{array}$} & Consumo energético \\
\hline & & Contaminación atmosférica \\
\hline & & Ruidos \\
\hline \multirow{4}{*}{ 2- Lavado } & \multirow{3}{*}{$\begin{array}{l}\text { Eliminación de la suciedad y restos } \\
\text { de materiales que son contaminantes } \\
\text { para el proceso }\end{array}$} & Generación de efluentes \\
\hline & & Consumo energético \\
\hline & & Generación de residuos \\
\hline & Ruido & Contaminación atmosférica \\
\hline \multirow{5}{*}{ 3- Molienda } & \multirow{2}{*}{$\begin{array}{l}\text { Transformación en pasta de la mate- } \\
\text { ria prima. }\end{array}$} & Consumo energético \\
\hline & & Consumo de Agua \\
\hline & Uso de combustible para la caldera & Contaminación atmosférica \\
\hline & Emisiones de Vapores & Contaminación atmosférica \\
\hline & Ruido & Contaminación atmosférica \\
\hline \multirow{4}{*}{ 4-Amasado } & \multirow{4}{*}{ Separación de fases por calor } & Consumo de Agua \\
\hline & & Consumo energético \\
\hline & & Contaminación atmosférica \\
\hline & & Ruidos \\
\hline \multirow{5}{*}{$\begin{array}{l}\text { 5- Centrifugación } \\
\text { horizontal }\end{array}$} & \multirow{4}{*}{ Separación de fase sólida y liquida } & Consumo energético \\
\hline & & Consumo de Agua \\
\hline & & Generación de residuo semisólido (orujo) \\
\hline & & Generación de residuo liquido (alpechín) \\
\hline & Ruido & Contaminación atmosférica \\
\hline \multirow{2}{*}{$\begin{array}{l}\text { 6- Centrifugación } \\
\text { Vertical }\end{array}$} & Separación de aceite y agua & $\begin{array}{c}\text { Generación residuos líquidos (Alpechín) } \\
\text { contaminación de suelos }\end{array}$ \\
\hline & Olores & Contaminación atmosférica \\
\hline 7- Almacenamiento & Decantación natural & Generación de residuos orgánicos \\
\hline 8- Fraccionamiento & Transporte del aceite & Consumo energético \\
\hline
\end{tabular}


Del análisis de esta matriz nos ocuparemos del punto seis (6) de centrifugación vertical, donde se obtiene el residuo líquido denominado alpechín, objeto del proyecto de investigación.

\section{COMPOSICIÓN DEL ALPECHÍN}

El caso del efluente líquido que se tratará se denomina alpechín y se obtiene de la elaboración del aceite de oliva, en un proceso de obtención de tres fases, en el que al ingresar las aceitunas son lavadas con agua potable, luego pasan por un molino para obtener una pasta homogénea que luego es amasada y después atraviesa una centrifugadora horizontal, que separa los residuos sólidos (orujo) y por último pasa a través de una centrifugadora vertical, que da el residuo liquido (alpechín). Del total de kilogramos procesados de aceitunas se obtiene de aceite de oliva un $20 \%$, un 30 $\%$ de residuos sólidos (orujo) y finalmente un $50 \%$ de residuos acuosos (Alpechín) ${ }^{3}$.

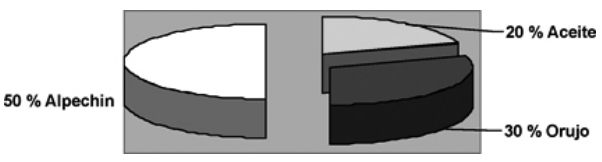

La composición química del alpechín es muy variable y función de numerosos factores como: la variedad del olivo, el tipo de suelo, el sistema de cultivo, el grado de madurez y el tiempo de almacenamiento del fruto y el sistema de extracción, factor este último que más condiciona la composición y cantidades del alpechín obtenido, ya que por cada kilogramo de aceituna procesado en un sistema de tres fases que proviene el alpechín a tratar se obtienen entre 0,5 a 1,4 litros y 0,5 kilogramos de orujo ${ }^{4}$.

El alpechín contiene el agua de la propia aceituna, las aguas de su lavado y procesado. Es un líquido de color negruzco y olor fétido que suele contener, en suspensión, restos de la pulpa de la oliva, mucílagos, sustancias pécticas e incluso pequeñas cantidades de aceite (un $0,5 \%$ emulsionado de forma estable).

El color del alpechín varía con el $\mathrm{pH}$ (rojizo a $\mathrm{pH}$ ácido y verdoso a $\mathrm{pH}$ alcalino), tiene sabor amargo, aspecto brillante y esta compuesto de un 83-94\% de agua, $4-16 \%$ de materia orgánica y $0,4-2,5 \%$ de sales minerales ${ }^{5}$.

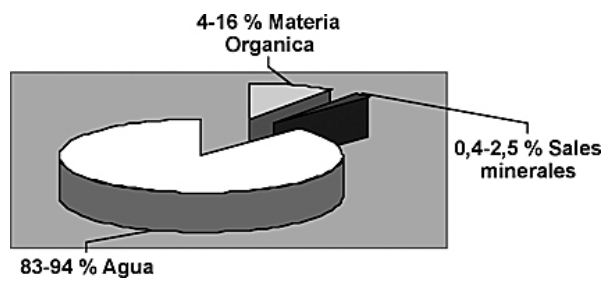

\footnotetext{
3 Fiestas Ros de Ursinos y Borja Padilla, 1992.

4 Sierra et al., 2001

5 Ramos-Cormenzana 1986
} 
La materia orgánica del alpechín está constituida por grasas, azúcares, sustancias nitrogenadas, ácidos orgánicos, polialcoholes, pectinas, mucílagos, taninos y polifenoles, que le confieren al alpechín tres de sus más importantes propiedades: el efecto bactericida, el efecto fitotóxico y el color 6 .

De los minerales posee altos contenidos en potasio, sodio, carbonato y fosfato, que pueden constituir el 47, 7, 21 y $14 \%$, respectivamente, del total de las sustancias minerales ${ }^{7}$.

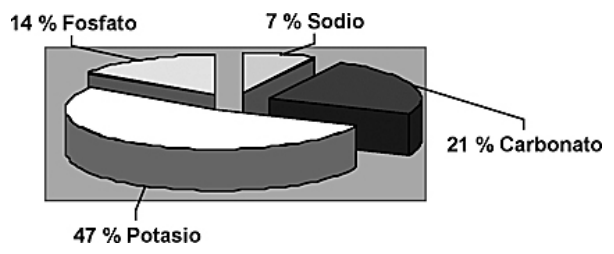

\subsection{PROPIEDADES DEL ALPECHÍN}

En el uso agronómico del alpechín podemos decir que tiene ventajas e inconvenientes 8 .

Ventajas:

1- Es una fuente barata de agua para riego.

2- Suministra al suelo nutrientes especialmente K

3- Materia orgánica.

Los Principales Inconvenientes:

1- Se producen grandes volúmenes en temporadas de bajo riego.

2- Elevada salinidad que ocasiona daños en los terrenos y plantas.

3- Posee bajo PH.

4- Abundante contenido de polifenoles que le confieren poder fitotoxico.

5- Contiene lípidos que impermeabilizan el terreno donde es vertido.

$\mathrm{Su}$ degradación en la naturaleza o en plantas depuradoras, es difícil básicamente debido a que posee compuestos con poder antibacteriano. Su efecto, en los ríos, playas, costas y campos, puede ser adverso y nocivo al ambiente porque produce suciedad, malos olores, mata plantas y peces.

Precisamente este tipo de efluentes difíciles de tratar, debe ser sometido a técnicas que se encuentran en la Ingeniería electroquímica, que se pondra en práctica en este trabajo.

\footnotetext{
6 Pérez et al., 1992

${ }^{7}$ Fiestas Ros de Ursinos y Borja Padilla, 1992

8 Tomati y Galli, 1992
} 


\section{OBJETIVO GENERAL}

- Recuperación electroquímica del agua del alpechín, para evitar la contaminación del medio ambiente y lograr su reutilización como agua de riego.

\subsection{OBJETIVOS ESPECÍFICOS}

- Contribuir al desarrollo sostenible de la comunidad, desde una perspectiva medioambiental, económica y social

- Disminución del consumo de agua de la red pública

- Reducción de los poli fenoles del alpechín

- Reducción de los lípidos

- Reducción de la salinidad del alpechín

- Eliminación de malos olores

- Aprovechamiento de la materia orgánica del alpechín como abono

- Aprovechamiento del potasio del alpechín

- Formar Recursos Humanos, tanto en el aspecto técnico como académico, con el fin de contribuir al desarrollo olivícola provincial.

\section{HIPÓTESIS}

"Aplicación de un tratamiento electroquímico al alpechín que disminuirá los compuestos polifenolicos que son la causa del efecto bactericida, fitotóxico y también la disminución de lípidos en suspensión, encargados del efecto impermeabilizante en los suelos con el objeto de su utilización como agua de riego"

\section{ESTADO ACTUAL DEL CONOCIMIENTO}

El sector productor del aceite de oliva, genera subproductos sólidos y líquidos que tienen una gran incidencia en la estructura técnico-económica y ambiental, en función de los volúmenes de producción.

En los últimos 25 años, las transformaciones tecnológicas en la elaboración de aceites de oliva, han tenido como objetivo mejorar la calidad del producto, racionalizar los diferentes procesos básicos y disminuir la alta dependencia de mano de obra.

La primera transformación relevante en España se produjo en los años 1.973-75, al utilizar en la separación sólido-líquido el decantador centrífugo horizontal. Con éste equipo, nuevos procesos, distribución de maquinaria, condiciones de trabajo, preparación del personal, higiene, etc, comenzó a cambiar la imagen tradicional de la producción de aceite de oliva.

Con el sistema continuo de centrifugación se cambiaron los conceptos de productos, composición y aprovechamiento de los subproductos orujo y alpechín, en base a sus nuevas características y por la tendencia a la ampliación y agrupación de produc- 
tores, que constituyeron sociedades capaces de abordar la nueva situación tecnológica, originando por estas causas el aumento y concentración de éstos subproductos.

En la Argentina en la región la región del noroeste producción olivícola, es una importante industria en la que sobresale la Provincia de La Rioja, es por ello que se aborda el problema de la contaminación ambiental, por el vertido del alpechín en los suelos y espejos acuíferos de la provincia, este problema surge por la demanda del progreso y la economía creciente en la provincia.

En nuestro país no se registran antecedentes publicados en el tema abordado en este trabajo de investigación, pero es sabido que en países Europeos como España e Italia se utilizan procesos similares que recién están saliendo de su etapa de laboratorio.

Cabe destacar que en este proyecto se emplea de referencia el trabajo realizado por la Universidad Nacional de Colombia, Sede Manizales que trata la depuración de efluentes lixiviados de rellenos sanitarios.

\section{METODOLOGÍA A EMPLEAR}

La metodología a emplear proviene de la Ingeniería Electroquímica que es la parte de la química que estudia la relación entre la corriente eléctrica y las reacciones químicas, como así también la conversión de la energía química en eléctrica y viceversa. En un sentido más amplio, la electroquímica es el estudio de las reacciones químicas que producen efectos eléctricos y de los fenómenos químicos causados por la acción de las corrientes o voltajes.

La corriente eléctrica es transportada en los conductores sólidos por el movimiento de los electrones; y en disoluciones y gases, lo hace por los iones que son átomo o grupo de átomos con carga eléctrica. Un átomo que pierde un electrón forma un ion de carga positiva, llamado catión; un átomo que gana un electrón forma un ion de carga negativa, llamado anión.

La elección de la técnica de depuración de electrocoagulación para este proyecto se debe a las características del efluente a tratar, el alpechín posee un alto poder contaminante, que se debe al elevado contenido de carga orgánica de baja biodegradabilidad (por la presencia de polifenoles que le dan un efecto fototóxico) de sus compuestos solubles, que no permiten la aplicación de tratamientos biológicos a bajo costo, ya que en los meses de cosecha se producen grandes cantidades de alpechín en corto tiempo, que no deben ser vertidos en cursos de aguas superficiales o red cloacal.

También una de las ventajas de la elección del método es que se pueden llevar a cabo reacciones que necesitan grandes cantidades de energía a temperatura y presión ambiente, en las que se utiliza a la corriente como agente oxidante en el ánodo y reductor en el casco, el reactivo (energía) es fácil de obtener en todo momento, no es necesario almacenarlo y se dispone de el justo en la medida que se necesita. 


\subsection{ELECTROCOAGULACIÓN}

El tratamiento a emplear en este proyecto es la electrocoagulación, que consiste en hacer pasar la energía eléctrica, a través de una cuba electrolítica con el efluente a tratar, el paso de la corriente se logra mediante la aplicación de una diferencia de potencial proveniente de una fuente de alimentación de CC, a través de 9 (nueve) elementos conductores (electrodos de Aluminio) insertos en el líquido. El líquido en el que se provoca la reacción química es conductor y la diferencia de potencial genera un paso neto de corriente eléctrica (electrones) entre los electrodos, con la consiguiente oxidación (transferencia electrónica hacia el electrodo desde la especie química) de algunas especies de la disolución en la superficie (electrooxidación) de uno de los electrodos positivo o ánodo y la reducción (transferencia electrónica desde el electrodo a la especie química) en el negativo o cátodo.

Los productos reducidos resultantes pueden pasar a formar parte del cátodo (electrodeposición), o pueden continuar en disolución (electrorreducción).

Contaminante \pm ne- $\rightarrow$ Compuesto Inerte

\subsection{REACCIONES DE LA ELECTROCOAGULACIÓN}

Este proceso posee varias reacciones que se detallan a continuación:

1. Una de las reacciones del proceso electroquímico es producir la desalinización $(\mathrm{NaCl})$ del efluente.

2. En otra reacción se produce la descomposición del material orgánico disuelto (polifenoles), que debe ser destruido en un proceso que denominamos Electrodigestión. En este caso la materia orgánica es sometida a procesos de oxidación y reducción en forma simultánea en la superficie de los electrodos (Reacción directa) de manera que la solución o efluente cumpla con el objetivo final de la conversión de la materia orgánica en elementos básicos de menor peligrosidad ambiental como son el $\mathrm{CO}_{2}, \mathrm{H}_{2} \mathrm{O}, \mathrm{Cl}_{2}$, etc.

3. También se producen dos reacciones importantes en la cuba, ya que cuando se electroliza un agua residual se produce la oxidación anódica y la reducción catódica del agua (ec. 2 y 3 ):

$2 \mathrm{H} 2 \mathrm{O} \rightarrow \mathrm{O}_{2}+4 \mathrm{H}++4 \mathrm{e}-(2)$

$2 \mathrm{H}_{2} \mathrm{O}+2 \mathrm{e}-\longrightarrow \mathrm{H}_{2}+2 \mathrm{OH}-(3)$

Estas reacciones consumen una parte importante de la energía eléctrica suministrada a los electrodos, ya que los electrones involucrados en las mismas no se dedican a la oxidación o reducción de los contaminantes contenidos en el agua residual, ni a la generación de especies que indirectamente realicen esta función, lo que ocasionará una disminución en las eficacias en el uso de corriente eléctrica. 
Figura que representa las diferentes reacciones químicas (oxidación y reducción)

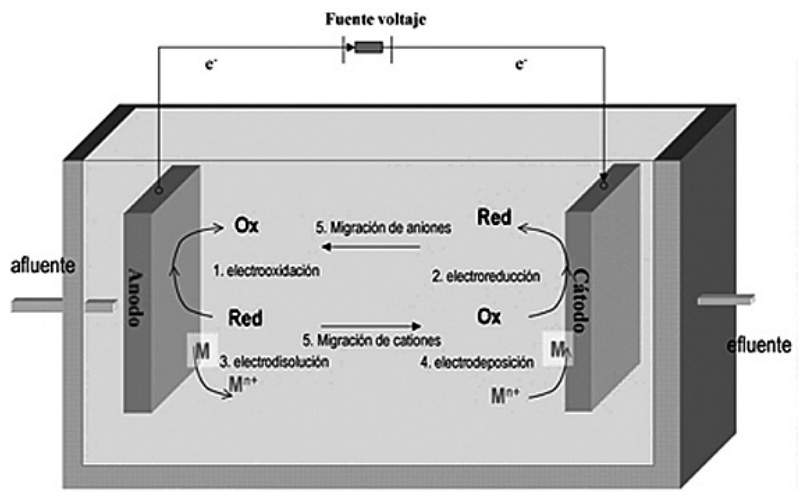

Esquema ilustrativo de la disposición de los componentes

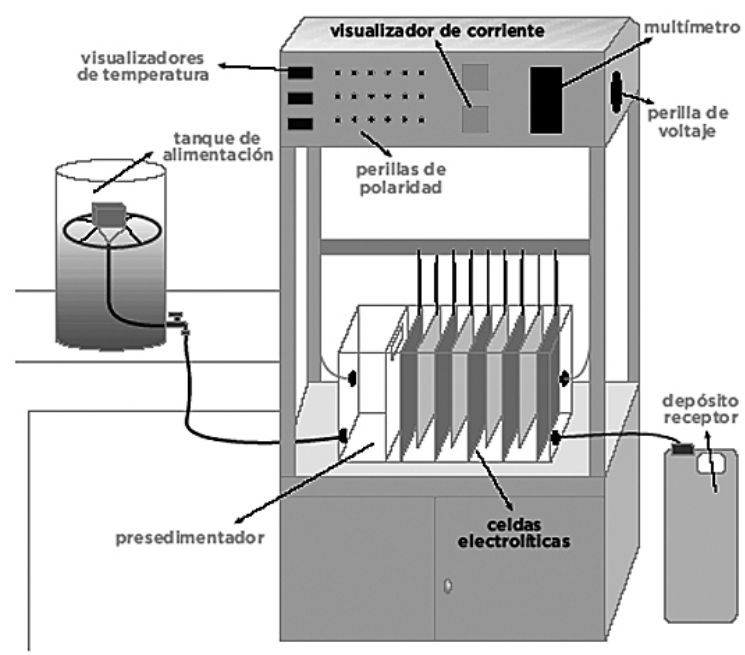

\subsection{EQUIPAMIENTO}

- Cuba electrolítica de vidrio de 20 × 30 × 40 capacidad 24 litros

- Nueve electrodos de aluminio de 19 × $25 \mathrm{~cm}$ (5 catodos y 4 anodos)

- Tres tanques para deposito con capacidad de 25 litros

- Fuente de alimentación de corriente continua CC de 12 v y 20 Amper

- Amperímetro

- Voltímetro

- Reóstato variable de $5 \Omega 7$ Amp.

- Manguera de Ø $7 \mathrm{~mm}$ con sistema sifón en un extremo que se coloca en el interior del tanque de vertido para tener la misma presión de salida 
- Manguera de desagote de la cuba al deposito de efluente tratado

- Sistema tipo sifón para obtener una presión constante a la salida del recipiente vertedor.

- Cronometro

- Un Peachimetro

- Termómetro

- Dos metros de cable unipolar de Ø $6 \mathrm{~mm}$

- Terminales para conectar los electrodos

- Recipientes para las muestras tratadas para analizar de $500 \mathrm{ml}$

\section{VARIABLES A CONTROLAR}

- Valores de tensión (Voltaje)

- Intensidad de la corriente (Amperes)

- Tiempo del proceso electroquímico

- Volumen de trabajo del efluente

- Conductividad eléctrica

- Valores de PH

- Caudal de trabajo

- Temperatura

\section{TAREAS A REALIZAR}

a. Toma de muestras de alpechín de la centrifuga vertical.

b. Control de parámetros fijos.

c. Ensayo del equipo con agua para establecer su normal funcionamiento

d. Conexión del equipamiento eléctrico y ensayos de laboratorio con agua

e. Ensayo de las muestras de alpechín.

f. Análisis de los resultados (los datos obtenidos de los análisis químicos de las distintas muestras, serán comparados).

g. Elección del proceso más eficiente.

\subsection{TRATAMIENTO DE LAS MUESTRAS}

a. La toma de muestras del alpechín se realiza en tres recipientes de 25 litros a la salida de la centrifugadora vertical.

b. Las muestras son llevadas al laboratorio y allí se miden los valores de temperatura y $\mathrm{PH}$. 
c. Armado del equipamiento de trabajo y puesta en marcha con agua para corroborar la circulación correcta del fluido, que debe ponerse en contacto con todas las superficies de los electrodos de aluminio y que el caudal de 14 litros/ minutos sea el correcto.

d. Al iniciar el proceso de depuración electroquímico, como primer paso se realiza la toma de muestra sin tratar a la salida del recipiente vertidor, para su posterior análisis como muestra patrón de los valores a reducir en el proceso (lípidos en suspensión y polifenoles), previo a esto se controlan los valores de temperatura, conductividad y $\mathrm{PH}$.

e. Luego se conecta la fuente de alimentación y comienza el vertido del efluente en la cuba electroquímica, en los primeros minutos del llenado de la cuba comienza a verse levemente un burbujeo sobre la superficie del efluente tratado en los diferentes compartimentos de la cuba, que corresponde a la liberación de gases (CO2, H2 y O2), por la descomposición de los compuestos orgánico (polifenoles) a causa de la oxidación directa sobre los electrodos (ánodo).

f. En la segunda etapa cuando el proceso entra en régimen, al circular los electrones entre los electrodos y los compuestos presentes en el efluente, se inicia el proceso de reducción en el cátodo (conversión de los protones del agua en hidrogeno) y el proceso de oxidación en el ánodo (generación de iones metálicos y oxigeno que provienen de la hidrólisis del agua), es por ello el burbujeo que se observa sobre toda la superficie de la cuba.

g. En la tercera etapa se produce sobre la superficie de la cuba, una floculación de los lípidos que se encontraban en el efluente.

h. Por ultimo se realiza la toma de muestra del efluente tratado para su posterior análisis, después de transcurrido $16 \mathrm{~min}$. que es el tiempo aproximado que tarda en pasar por la cuba el efluente.

La primera experiencia se realiza con los siguientes valores:

- Valores a controlar después del proceso de depuración

- Aceite y grasa en suspensión del efluente

- Cantidad de polifenoles en el efluente

- Conductividad eléctrica

\section{ENSAYOS DE LA MOLIENDA 2010}

Los valores de referencia corresponden a los limites de Tolerancia dispuestos por la Ley Provincial No 4741, modificada por Decreto 773 regl. de la Ley No 6281 para efluentes industriales vertidos a colectora cloacal. Los métodos utilizados son aceptados por la APHA (Standard Methods for the Water and Wastewater). 


\begin{tabular}{|l|l|}
\hline \multicolumn{2}{|c|}{ MUESTRA N $^{\mathbf{0}}$ PROTOCOLO 93407 } \\
\hline Medición de PH & 3,3 \\
\hline Temperatura & $25^{\circ} \mathrm{C}$ \\
\hline Contenido de fenoles & $0,166 \mathrm{mg} / \mathrm{lt}$ \\
\hline Voltaje & 2 \\
\hline Amperes & 12,5 \\
\hline Tiempo & $16 \mathrm{~min}$ \\
\hline Caudal de trabajo & $1,4 \mathrm{lts} / \mathrm{min}$ \\
\hline
\end{tabular}

\begin{tabular}{|l|l|}
\hline \multicolumn{2}{|c|}{ MUESTRA N ${ }^{\mathbf{0}}$ PROTOCOLO 93408 } \\
\hline Medición de PH & 3,8 \\
\hline Temperatura & $24{ }^{\circ} \mathrm{C}$ \\
\hline Contenido de fenoles & $0,150 \mathrm{mg} / \mathrm{lt}$ \\
\hline Voltaje & 2,5 \\
\hline Amperes & 18,5 \\
\hline Tiempo & $16 \mathrm{~min}$ \\
\hline Caudal de trabajo & $1,4 \mathrm{lts} / \mathrm{min}$ \\
\hline
\end{tabular}

\section{ENSAYOS DE LA MOLIENDA 2011}

\begin{tabular}{|l|l|}
\hline \multicolumn{2}{|c|}{ MUESTRA PATRON PROTOCOLO No 3691 SIN TRATAR } \\
\hline Medición de PH & 4,8 \\
\hline Temperatura & $19^{\circ} \mathrm{C}$ \\
\hline Conductividad & 140 \\
\hline Contenido de fenoles & $0,12 \mathrm{mg} / \mathrm{lt}$ \\
\hline Contenido de grasa y aceites & $29 \mathrm{mg} / \mathrm{lt}$ \\
\hline
\end{tabular}

\begin{tabular}{|l|l|}
\hline \multicolumn{2}{|c|}{ MUESTRA TRATADA PROTOCOLO N $\mathbf{N}^{\mathbf{3}} \mathbf{3 6 0}$} \\
\hline Medición de PH & 6,1 \\
\hline Temperatura & $19{ }^{\circ} \mathrm{C}$ \\
\hline Conductividad & 50 \\
\hline Contenido de fenoles & $0,10 \mathrm{mg} / \mathrm{lt}$ \\
\hline Contenido de grasa y aceites & $22 \mathrm{mg} / \mathrm{lt}$ \\
\hline Voltaje & 8 \\
\hline Amperes & 23 \\
\hline Tiempo & $16 \mathrm{~min}$ \\
\hline Caudal de trabajo & $1,4 \mathrm{lts} / \mathrm{min}$ \\
\hline
\end{tabular}

Los valores de referencia corresponden a los limites de Tolerancia dispuestos por la Ley Provincial No 4741, modificada por Decreto 773 regl. de la Ley $\mathrm{N}^{\circ} 6281$ para efluentes industriales vertidos a colectora cloacal. Los métodos utilizados son aceptados por la APHA (Standard Methods for the Water and Wastewater). 


\section{RESULTADOS}

\begin{tabular}{|l|c|}
\hline \multicolumn{1}{|c|}{ Muestra cosecha 2010 } & Concentración de Fenoles mg/lit \\
\hline Muestra tratada II & 0,166 \\
\hline Muestra tratada III & 0,150 \\
\hline
\end{tabular}

Reducción de un $10 \%$ de Fenoles

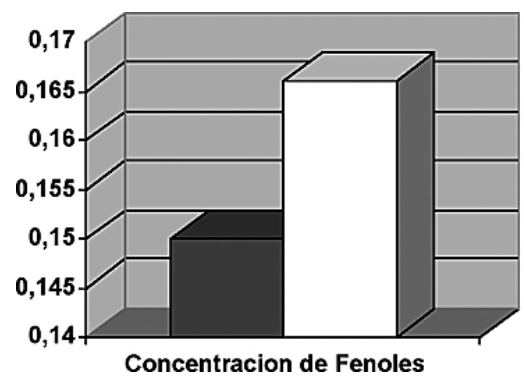

\begin{tabular}{|l|c|c|c|}
\hline Muestra cosecha 2011 & Conductividad & $\begin{array}{c}\text { Concentración de } \\
\text { grasa y aceites mg/lt }\end{array}$ & $\begin{array}{c}\text { Concentración de } \\
\text { Fenoles mg/lt }\end{array}$ \\
\hline Patrón & 140 & 29 & 0,12 \\
\hline Muestra tratada & 50 & 22 & 0,10 \\
\hline
\end{tabular}

Reducción de un $35 \%$ en la conductividad y un $21 \%$ en grasas y aceites

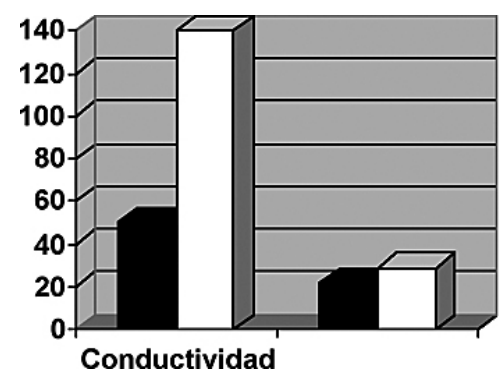

Reducción de un $17 \%$ de Fenoles

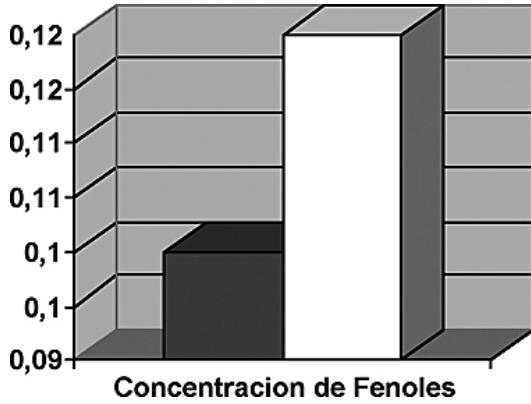

Concentracion de Fenoles $\square$ Muestra Tratada

$\square$ Muestra Patron 
El residuo orgánico que se obtiene de la floculación es recolectado para ser disecado y utilizado como abono.

En el análisis de los costos de Producción del Aceite de Oliva se estableció, que los gastos de energía eléctrica, para la implementación del proceso redepuración se incrementaran en un aumento del $6 \%$ en el precio final del litro de aceite de oliva producido.

\section{CONCLUSIÓN}

En la realización de los ensayos se tuvo en cuenta las siguientes premisas, en primer lugar se efectuó el primer ensayo en la campaña 2010 con valores de tensión y corriente similares a los de la descomposición electrolítica del agua, 2 voltios de tensión y 12,5 Amper de corriente, con el objeto de establecer que variación producían en el efluente tratado, en el segundo ensayo también en 2010 se aumentó en un $25 \%$ la tensión y un $50 \%$ el valor de corriente, con respecto a los valores de corriente y tensión del primer ensayo. En los ensayos sobre las muestras de la campaña 2011 se trabajo con un valor de tensión cuatro veces mayor que el valor del primer ensayo de 2010 y se duplicó la corriente, estableciendo que con estos valores, se lograba el mejor rendimiento en la proceso de depuración.

El análisis de las primeras muestras que se realizaron al finalizar la campaña, se estableció que al aumentar los valores de tensión y corriente, se obtenía una reducción del contenido de polifenoles, se trabajo con dos muestras, una experiencia se realizó con una tensión de 2 volts y 12,5 Amper de corriente y la otra muestra se trato con valores de 2,5 volts para la tensión y 18,5 Amper de corrientes, estos valores mas elevados dieron como resultado una reducción del $10 \%$ en la concentración de fenoles en el efluente y no se tuvo en cuenta los lípidos, ni la conductividad del efluente.

En la segunda experiencia de fecha a mitad de campaña del año 2011 se trabajó con una muestra patrón que registró un valor de polifenoles de $0,12 \mathrm{ml} / \mathrm{lt}$, conductividad 140 mili vol y un contenido de grasa y aceite de $29 \mathrm{mg} / \mathrm{lt}$, al tratar esta muestra con los valores de tensión de 8 vol y 23 Amper en un tiempo de 16 minutos, se estableció en los análisis realizados, el cumplimiento de nuestra hipótesis, ya que al aplicar al efluente denominado alpechín un proceso electroquímico, este sirve para utilizarse como agua de riego, al observarse en los valores de los análisis, una reducción aproximada de un 17 $\%$ en concentración de Fenoles, una reducción aproximada de un $21 \%$ en la concentración de grasas y aceites y una reducción aproximada de un $35 \%$ en la conductividad.

En función de los resultados obtenidos, se puede plantear la posibilidad de la implementación y puesta en marcha de una planta depuradora, que permita el tratamiento integral y valorización de los residuos, generados en la producción del aceite de oliva.

También se puede demostrar que es posible llevar a cabo la producción de aceite de oliva, teniendo en cuenta el cuidado del medio ambiente y producir un ahorro del agua utilizada en el riego de los olivares del parque tecnológico.

Además el agua depurada no producirá malos olores, favorece al entorno social que no sentirá olor alguno al realizarse el riego de los olivares y desde luego debe tenerse en cuenta, el importante aporte al suelo de materia orgánica y potasio al realizar el riego con el alpechín tratado. 


\section{REFERENCIAS}

COEURET, F. "La Ingeniería Electroquímica" - INGENIERIA QUIMICA- 315. 105. (1995).

OCHOA, J.R. "Técnicas Electroquímicas para el tratamiento de efluentes industriales". -INGENIERIA QUIMICA- 312. 125. (1995).

ALBA MENDOZA, J. 1994a. Nuevas tecnologías para la obtención de aceite de oliva. Olivicultura. Fundación La Caixa y Agro Latino, Barcelona, pag. 85 - 95.

AMA 1992. Alpechines: situación actual de las tecnologías de depuración. Informe $\mathrm{N}^{\circ}$ 6/92. Dpto. Investigación. Consejería de Cultura y Medio Ambiente. Junta de Andalucía.

GARCIA RODRIGUEZ, A. 1990. Eliminación y aprovechamiento agrícola del alpechín. Reunión Internacional sobre Tartamiento de Alpechines, Córdoba.

MERCADO MARTINEZ, I. D. y Reyes Avila, D. "Estudio de tartabilidad por electrocoagulación de los lixiviados del relleno sanitario "La Esmeralda" Trabajo de grado, Univ. Nacional de Colombia, Manizales (Diciembre 2003).

MARTINEZ, S. et al. "Tratamiento electrolítico de efluentes industriales" Revista del Instituto Mexicano del Petróleo (1990) Vol. 22, N 3.

MERCADO, I. et al. "La Electroquímica en Función de la Ingeniería Ambiental. Método de electrocoagulación Aplicado a un Flujo Continuo de Residuos Líquidos" Revista Residuos (2006) N 94, pp 62 - 65.

NUEVA OLIVICULTURA - Andrés Guerrero García "El alpechín como abono orgánico" año 2.003 pagina 120 , quinta edición.

BIOTECNOLOGIA AMBIENTAL - Francisco Castillo Rodríguez; Maria Dolores RoldanRuiz, Rafael Blasco Pla; Maria José Hertas Romera; Francisco J. Caballero Domínguez; Conrado Moreno Vivian; Manuel Martínez Luque Romero. 